\title{
Monitoring sterilization of dressings in high-vacuum pressure-steam sterilizers ${ }^{1}$
}

\author{
R. J. FALLON ${ }^{2}$ \\ From the University Department of Bacteriology, Western Infirmary, Glasgow
}

SYNOPSIS Undetected air leaks in a high-vacuum sterilizer can defeat the sterilization process. For this reason the maintenance and supervision of these sterilizers needs expert engineering care. The importance of controlling the high-vacuum sterilization process from the centre of a load rather than the chamber drain is emphasized, and a method of detecting any failure in a high-vacuum process is described. The dynamics of the high-vacuum sterilization process are discussed and the possible disadvantages of an integrator are noted. The wisdom of using a temperature of $134^{\circ} \mathrm{C}$. for three minutes is questioned.

Any delay in steam penetrating into a load in a highvacuum, high-speed sterilizer can defeat the sterilization process. The holding time at $134^{\circ} \mathrm{C}$, , the temperature of steam at 30 pounds per square inch (p.s.i.), is only three minutes, and although such a rapid process increases the turnover of a sterilizer, the wisdom of having such a short exposure time to steam has been questioned by Knox (1961). In most of the sterilizers at present in use the steaming time is taken from the moment when the chamber drain reaches the temperature of saturated steam at the pressure employed. However, it has been shown (Fallon, 1961) that this temperature may be misleading if steam penetration is delayed due to deficiencies in the fore-vacuum drawn before steam is admitted to a high-vacuum sterilizer. Normally the level of vacuum is monitored so that steam is not admitted to the chamber until a vacuum of $20 \mathrm{~mm}$. $\mathrm{Hg}$ absolute pressure or better is reached. Not only could such a monitoring system become faulty but, as has been noted (Fallon, 1961), the fore-vacuum can be defeated by an undetected leak in the sterilizer. The present paper describes experimental work on the effect on steam penetration into a load exposed to steam at 20 or 30 p.s.i. of a known and measurable leak. It deals also with a suitable monitoring system to detect delays in steam penetration due to this or any other cause.

The first indication I had of the importance of a

\footnotetext{
${ }^{1}$ Report to the Medical Research Council Working Party on Pressuresteam Sterilizers.

${ }^{2}$ Present address: Pathology Department, Ruchill Hospital, Glasgow, N.W.

Received for publication 20 June 1961.
}

leak in delaying steam penetration into a load in a high-vacuum sterilizer was when I was asked to examine a $60 \mathrm{cu}$. ft. high-speed, high-vacuum sterilizer which failed to change Browne's tubes No. II (yellow spot) from red to green even with nine minutes' steaming at 134 to $136^{\circ} \mathrm{C}$. The forevacuum drawn by this machine was found to be $16 \mathrm{~mm}$. $\mathrm{Hg}$ absolute pressure even in the presence of a gross air leak. Thermocouples were placed in a load of gowns and towels in a cylindrical dressing drum. In the first experiment (Fig. 1a), in which the thermocouples were introduced round the door of the sterilizer, a remarkable delay in steam penetration into the load was observed. When the thermocouples were placed through a leak-proof fitting the delay was less dramatic (Fig. 1b) but was still extremely serious. The reason for this delay was not clear at that time but when a diaphragm controlling the door-locking mechanism was replaced shortly afterwards, all Browne's tubes placed in loads changed to green quite satisfactorily after a sterilizing run. The probability that the delay was due to an air leak was investigated in an experimental sterilizer.

\section{EXPERIMENT}

The $4 \cdot 2 \mathrm{cu}$. ft. high-vacuum experimental sterilizer with which this work has been carried out has already been described in detail (Fallon, 1961). The test loads consisted of cotton huck towels measuring 20 in. $\times 30$ in. For most experiments 16 towels were used packed so that they lay in a horizontal plane when placed in the sterilizer, i.e., in a position which would delay steam penetration by downward displacement. Normally they were wrapped in a further two towels to simulate a 


\section{Thermocouples round door (Gross air leak)}

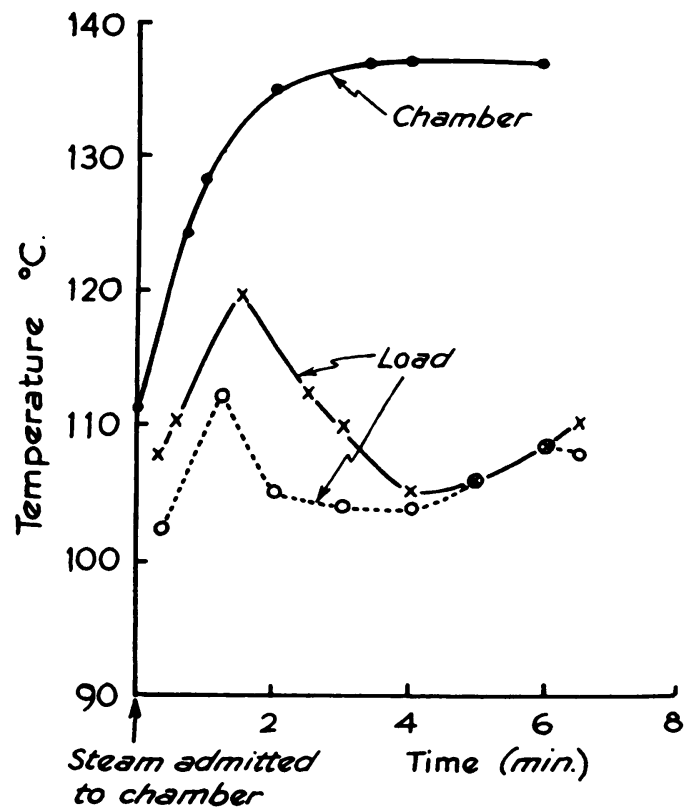

Thermocouples inserted through leakproof fitting

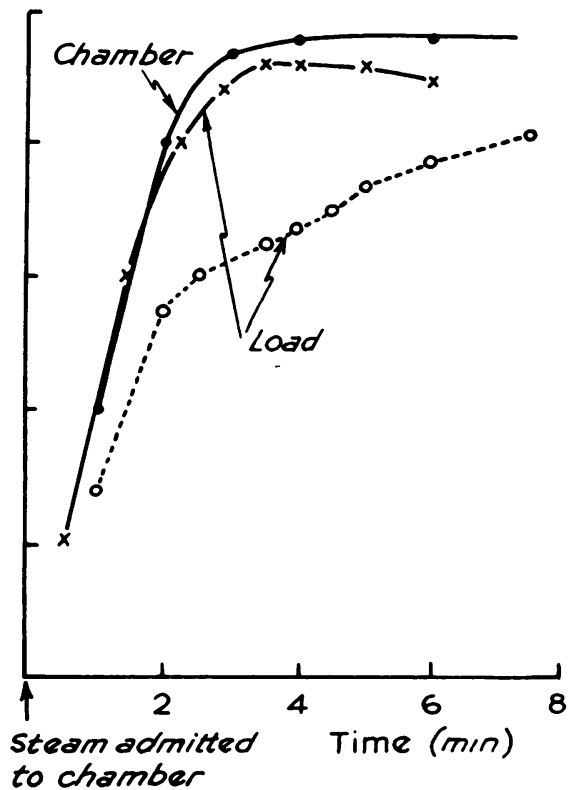

FIG. 1. Temperature rise inside a 60 cubic foot high-vacuum sterilizer. One thermocouple was free inside the chamber. The other two were placed inside a drum containing gowns and towels.

drum lining and were then placed in a cylindrical dressing drum 10 in. diameter by 9 in. deep. Results similar to those described below were obtained with only eight towels in a drum or with loads in a cardboard box. The temperature at six standard points in each container was measured, using thermocouples connected to a high-speed electronic recorder.

A small leak was introduced into the sterilizer through the test cock on the door. The leak was one that produced a rise in pressure of 2.5 to $3.5 \mathrm{~mm}$. $\mathrm{Hg}$ over a period of one minute when the chamber was evacuated to 20 $\mathrm{mm}$. $\mathrm{Hg}$ absolute. The vacuum pump performance was not affected by the presence of such a leak, the pumpdown time being the same whether the leak was present or not.

With a leak of this order $43.1 \mathrm{cu}$. in. $(707 \mathrm{ml}$.) of air leaked into the sterilizer during the period of one minute in which the pressure was raised from $20 \mathrm{~mm}$. $\mathrm{Hg}$ absolute to atmospheric by the incoming steam. The effect of such a leak on the temperature rise in a load is shown in Fig. 2. It may be seen that with no leak the rise in temperature inside a load to $126^{\circ} \mathrm{C}$. (that of saturated steam at 20 p.s.i.) was rapid and was reflected accurately by the chamber drain thermocouple. Furthermore, during the rise in pressure from atmospheric to 20 p.s.i. the load was always at a temperature corresponding to the pressure of saturated steam in the chamber. With a leak, steam penetration was delayed to a considerable extent and this delay was not shown by the chamber drain thermocouple. Similar results were obtained using steam at a pressure of 30 p.s.i. Slightly larger leaks (approximately $1,100 \mathrm{ml}$.) caused a much longer delay in steam penetration but also tended to increase the pumpdown time.

In order to try to understand just how a leak interferes with steam penetration the following experiment was performed. A fore-vacuum down to $15.8 \mathrm{~mm}$. $\mathrm{Hg}$ absolute was drawn. Enough air was then admitted to the chamber to bring the pressure up to $20 \mathrm{~mm}$. $\mathrm{Hg}$ absolute. Steam was then admitted to the chamber in the usual way. A gross delay in penetration was observed (Fig. 2). The load was exposed for as long a period to the vacuum as in experiments conducted without any leak of air, in which steam penetrated immediately. The results suggest that a leak does not interfere with steam penetration merely by bringing the effective fore-vacuum to over $20 \mathrm{~mm}$. $\mathbf{H g}$.

In the $60 \mathrm{cu}$. $\mathrm{ft}$. sterilizer which first showed this fault, the extensive use of Browne's tubes throughout the load revealed the failure to reach sterilizing conditions. However, it is little consolation to open a 'sterilized' package only to find that the indicator reveals the package not to be sterile; again it will be difficult to place a Browne's tube in every package used in a central sterile supply service. In order to overcome this difficulty a dummy load was devised from which the sterilizing cycle could be monitored and experiments have shown that this gave useful and reproducible results. The load consisted of a 


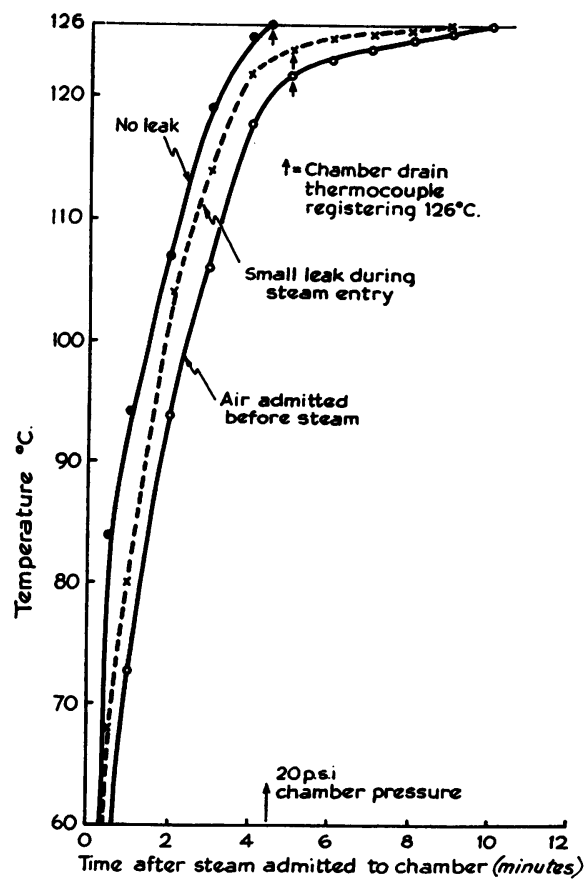

FIG. 2. Slowest rise of temperature recorded by six thermocouples placed inside a load of 16 cotton huck towels.

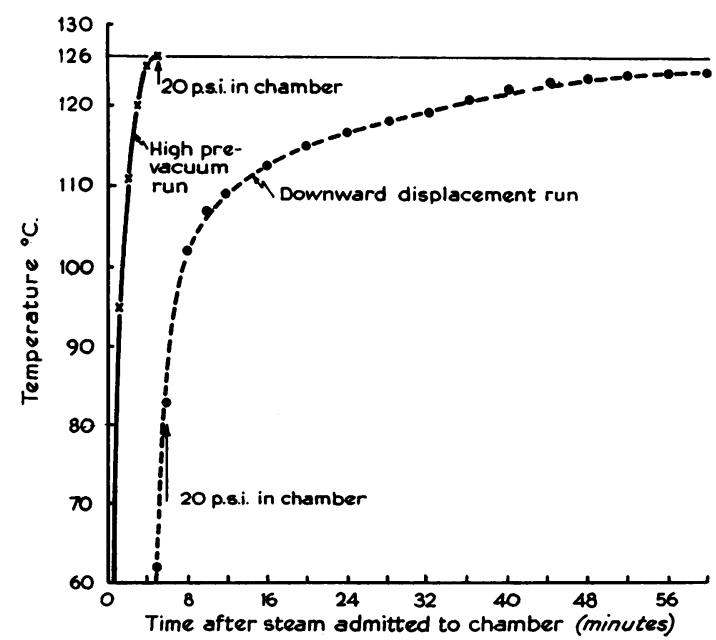

FIG. 3. Rise of temperature recorded by a thermocouple placed in the middle of the dummy drum.
10 in. diameter $\times 4 \frac{1}{2}$ in. deep cylindrical dressing drum packed tightly with $1,427 \mathrm{~g}$. of asbestos wool. Asbestos wool was used because, unlike cotton, this would not alter in nature with repeated sterilization and yet it was a fibrous material. A drum was used because this was a convenient container for the fibre. A thermocouple was placed in the centre of the load and the lead entered the $\stackrel{\mathbb{Q}}{\triangle}$ drum from the bottom when it was placed on its side in the sterilizer. Other containers, such as wire mesh baskets or a solid box open on one side only, were not successful; ? nor was a block of compressed asbestos. The load was designed so that it could not be penetrated by steam $\vec{\omega}$ (using the downward displacement method) in the period of time normally allowed for this to take place, yet it was? instantaneously penetrated by steam using a high-vacuum $\vec{A}$ process (Fig. 3). The delay due to the presence of a leak os in the sterilizer was well shown by the dummy drum. It $\dot{ }$ ) was found important to remove the drum from the $\&$ sterilizer between runs; otherwise heat from the jacket $ᄋ$ caused superheating on exposure to steam. This would tend to obscure any lag in temperature rise due to a leak.

\section{DISCUSSION}

These experiments show that if a high-vacuum sterilizer has a leak which is so small that it can be $\vec{\bullet}$ overcome by the vacuum pump supplied, the air $\stackrel{\circ}{\rightarrow}$ which leaks into the sterilizer, during the period when the pump is switched off and the steam entering the chamber raises the pressure to atmospheric, can seriously delay steam penetrating into a load. This defect may be detected by using large numbers of Browne's tubes, or, perhaps, by observing a delay in drawing the vacuum. It should be detected during a full engineering examination of a sterilizer by using a sensitive vacuum gauge. However, this fault may occur at any time and it may best be detected by monitoring the actual conditions in a load which is difficult to sterilize. The chamber drain temperature does not reflect accurately the conditions in the centre of a load when there is a leak (see Fig. 2) nor when there is an inadequate fore-vacuum (Fallon, 1961), and there can be no doubt that the only way of ensuring that a load has been subjected to an adequate sterilizing process is to record what temperature has been reached at the centre of the load and for how long this temperature has been maintained. The dummy load described above is $N$ suitable for this purpose as it can only be penetrated rapidly by steam when an adequate fore-vacuum has been drawn. The dummy load with a permanently fixed thermocouple or other temperature-sensitive device has a further advantage in that it will avoid $\stackrel{5}{?}$ the possibility of human error in placing the thermocouple into a load in such a way that steam will reach the temperature-sensitive end too easily, either because the thermocouple is placed in the superficial layers of a drum or pack (or even in a very 
small container), or because a track is left alongside the thermocouple lead. The thermocouple in the dummy load could not only be connected to a recorder but possibly also to an integrator, such as that described by Bowie (1961), covering a narrow range of time-temperature conditions. In this way the best possible control of the sterilizing process may be achieved. It is possible that two such dummy loads should be used, one for each alternate run, in order that the load should cool adequately between runs.

There is no doubt that a high-speed, high-vacuum sterilizer needs very careful and expert engineering supervision and there is ample room for doubt not only whether such supervision is easily available in all hospitals but whether sterilizers are checked often enough.

The experiment where only enough air was admitted to the chamber to bring the pressure up from $15.8 \mathrm{~mm}$. $\mathrm{Hg}$ to $20 \mathrm{~mm}$. $\mathrm{Hg}$ absolute throws a light on the dynamics of the high-vacuum sterilizing process. This experiment (which was repeated on several occasions) showed that it was the actual air which leaked in and not the change in absolute pressure which interfered with steam penetration. If the theory is correct that during the high forevacuum water is vaporized from the dressings and sweeps out the residual air (Lancet, 1959), it may be that not only does the water vapour scavenge air from the load but it may also aid air-scavenging from the chamber by the vacuum pump. When loads of 10 towels were placed in a dressing drum in the sterilizer and exposed to a vacuum falling from 20 to $16 \mathrm{~mm}$. $\mathrm{Hg}$ absolute for as short a time as three minutes, it was found that their weight fell by about $5 \mathrm{~g}$. (the load weighing about $860 \mathrm{~g}$.). At a pressure of $15.8 \mathrm{~mm}$. $\mathrm{Hg}$ absolute and a temperature of $18 \cdot 3^{\circ} \mathrm{C} .\left(65^{\circ} \mathrm{F}\right.$.) this amount of water, as vapour, would occupy a volume of 11.26 cubic feet $(318.9$ litres) and obviously the generation of such an amount of water vapour would aid air-scavenging from the sterilizer. If it is remembered that $\mathbf{1 0}$ towels represent a very small load and that the temperature within the chamber (in a sterilizer with a heated jacket) will be over $18^{\circ} \mathrm{C}$. in normal circumstances, it can be seen that this effect may be very important. When this scavenging of air is defeated by a leak, the air that is in the chamber may well be carried back into the load as the incoming steam rushes in to condense on the vast surface of the fibres of the dressings. This hypothesis explains not only what happens when a leak allows air to get back into the chamber but also why it is essential to hold the vacuum and not merely reach a level of $20 \mathrm{~mm}$. $\mathrm{Hg}$ and then immediately let steam into the chamber (Bowie, 1961). As noted in the M.R.C. report (Lancet,
1959), an absolute pressure of $20 \mathrm{~mm} . \mathrm{Hg}$ is above the level at which water will boil at room temperature and it is not easy to see why the level of $20 \mathrm{~mm}$. Hg should be an adequate fore-vacuum. The answer probably lies in the fact that the chamber will be much hotter than room temperature and also that some vacuum pumps will pump to a level below 20 $\mathrm{mm}$. $\mathrm{Hg}$. absolute during the holding period of vacuum allowed for on some commercial models. The hypothesis would also explain why inadequate degrees of fore-vacuum, i.e., above $20 \mathrm{~mm}$. $\mathrm{Hg}$ absolute, result in a delay in steam penetration into a load (Knox and Penikett, 1958; Fallon, 1961).

The observation that a leak delays steam penetration into a load and the possible explanation for this noted above raises the question of the value of an integrator on a sterilizer in the presence of a leak or faulty fore-vacuum. In a normally functioning high-vacuum sterilizer the time-temperature integrator can be brought into action as soon as the load reaches, say, $121^{\circ} \mathrm{C}$., as this temperature is due to the presence of saturated steam which will sterilize at this temperature. The time the load is above this temperature may be computed by an integrator until an adequate sterilizing period has been achieved. If, however, there is a leak, the rise in temperature in the load is delayed compared with the temperature in the chamber and this clearly must be due to the presence of air. In this case it is not permissible to integrate the time-temperature conditions until the load reaches the temperature corresponding to the pressure of steam in the chamber. Hence, although an integrator is a useful addition to a perfectly functioning sterilizer, it is clearly vital that a monitoring system should also be attached to a recorder so that any fault in the sterilizing process will be evident to the sterilizer supervisor who can then take appropriate action.

In view of the many snags that can arise, the wisdom of using a temperature of $134^{\circ} \mathrm{C}$. (30 p.s.i.) for three minutes as a sterilization process should be carefully reconsidered because the margin of safety is extremely small and may be unobtrusively exceeded by quite small leaks of air.

I am grateful to Dr. E. A. Bruges, Senior Lecturer in Mechanical Engineering in the University of Glasgow, for helpful discussions.

\section{REFERENCES}

Bowie, J. H. (1961). Paper presented at a Symposium on "Recent Developments in the Sterilization of Surgical Materials", held at the London School of Pharmacy, April 11-13th, 1961 (see Pharm. J., 186, 366).

Fallon, R. J. (1961). J. clin. Path., 14, 505.

Knox, R. (1961). Ibid, 14, 11.

, and Penikett, E. J. K. (1958). Brit. med. J., 1, 680.

Medical Research Council Working Party on Pressure-steam Sterillizers (1959). Lancet, 1, 425. 